\title{
Entrevista a Patrick Johansson, diretor da cátedra sobre a cultura Náhuatl na Universidade Nacional Autónoma de México (UNAM)
}

\author{
Luz María Tena Colunga \\ DOI: 10.26512/interethnica.v22i1.11300 Universidad Nacional Autónoma de México \\ e-mail: luzmatena@gmail.com
}

Resumo: A língua Náhuatl tem grande importância por ter sido a língua franca do Império Mexicano desde o século XIII, até a queda dele, pela conquista da Espanha em 1521. É a língua originária com maior número de falantes no México e tem falantes noutros países na Centroamérica, tais como o Salvador, a Nicarágua, a Guatemala, e a Honduras. O Seminário da Cultura Náhuatl foi fundado há 62 anos e nesta entrevista o Doutor Johansson compartilha a sua experiência, e nos fala sobre a importância de terem seminários da cultura e línguas originárias nas universidades dos países que temos pluriculturalidade como o Brasil e o México.

Palavras-chave: Náhuatl, México, Línguas Originárias.

\begin{abstract}
The Náhuatl language is very important since it was Lingua Franca of the Mexica Empire (XIIIth century) until the Spanish conquered in 1521. Nevertheless, nowadays is the original language with more speakers in México and has speakers in some other countries such as Salvador, Nicaragua, Guatemala and Honduras. The Seminario de Cultura Náhuatl was founded 62 years ago, and in this interview, Dr Johansson share his experience and tell us about the importance of having such seminars at universities in countries with a lot of ethnics cultures, such as Brazil and Mexico.
\end{abstract}

Keywords: Náhuatl, Mexico, Original Language.

Patrick Johansson doutor em Letras pela Universidade Sorbonne de Paris, investigador titular "C" no Instituto de Investigações Históricas na UNAM, onde também ministra as cátedras de Literatura Náhuatl e Maya e é diretor da cátedra da Cultura Náhuatl. É membro do Conselho da Crônica da Cidade de México: Sociedade de Escritores em Línguas Indígenas. Ocupa a terceira cadeira na Academia Mexicana da Língua e é membro correspondente na Real Academia Espanhola desde 2009.

É Diretor da cátedra da Língua e Cultura Náhuatl da Universidade de Colima (México) desde 1995 e Editor e articulista da Revista de Estudios de Cultura Náhuatl. Entre suas publicações mais recentes destacam-se Miccacuicatl. Las exequias de los señores mexicas (2006), Variaciones del español en México, (coordinación) Academia Mexicana de la Lengua, (2015); In oc ticchíah in Godot, tradução de Esperando a Godot (francês ao náhuatl, 2007); La palabra, la imagen y el manuscrito. Lecturas indígenas de un texto pictórico en el siglo XVI, (2004); Ángel María Garibay: la rueda y el río, coautoria com Miguel León-Portilla, 1993 e 2013. 
A cátedra da Cultura Náhuatl na UNAM foi fundada em 1956 e dirigida pelo humanista mexicano Angel María Garibay K. Está vinculado à Faculdade de Filosofia e Letras, e ao Instituto de História, hoje, Instituto de Pesquisas Históricas da UNAM. Garibay K. foi o diretor do seminário até o ano da sua morte em 1967. Foi substituído pelo Doutor Emérito León-Portilla até 2014 e, desde então por Johansson Keraudren. A língua Náhuatl tem grande importância por ter sido a Língua Franca do Império Méxica desde o século XIII, até a conquista Espanhola em 1521. É a língua originaria com maior número de falantes no México, além de ter outros falantes em países de Centro América como em El Salvador, Nicarágua, Guatemala e Honduras.

A importância de recuperar e fazer acessível a língua e a cultura Náhuatl, tem sido o objetivo primordial da cátedra desde sua fundação. Nesse sentido, atribui-se centralidade à percepção indígena de sua própria história e cultura. A cátedra tem permitido grande quantidade de publicações como livros, monografias e própria revista de Estudios de Cultura Náhuatl. Esse material é acessível mediante o site do Instituto de Investigaciones Historicas da UNAM.

A cátedra consta de duas horas de aula às terças-feiras, e é parte da formação profissional dos pós-graduandos de História, Estudos Mesoamericanos, Antropologia, além de outros cursos. Também podem participar das aulas estudantes de diversas universidades, indígenas e pessoas interessadas, independente da formação escolar.

P: Desde 1979 você tem acompanhado a cátedra da Cultura Náhuatl, quando Miguel León-Portilla era o diretor, e quem mais tarde, lhe nomeou assistente em 1993. A partir de 2015 tornou-se diretor da cátedra que teve origem em 1956.

Por ocasião do 62 aniversário da cátedra gostaria que ponderara
sobre seu desenvolvimento e a contribuição
pluriculturalidade no México.

R: A língua e a cultura Náhuatl voltou a crescer em importância enquanto ferramenta para compreender a história pré-hispânica. E, também para entender, neste tempo presente, as formas de percepção sobre a vida pelos grupos indígenas falantes do Náhuatl ou "nahuatlatos". Outro aspecto político e cultural significante diz respeito ao deslocamento e reconhecimento como língua, pois, no passado, foi chamada de "dialeto".

\section{P: Por quê?}

R: Há muito tempo, no século XIX, a língua e a cultura Náhuatl, não era valorizada no México. Era considerada um dialeto, assim como as outras línguas mesoamericanas, não importando o fato de continuarem a ser faladas nas regiões originárias e de serem um dos meios de comunicação para transmitir a sabedoria.

A cultura Náhuatl pré-hispânica mostrava a sua sabedoria e a sua história em códigos pictográficos. Então o sábio, chamado de "tlamatinime” em língua Náhuatl, transmitia o conhecimento na oralidade. 
Valorar e avaliar a Cultura Náhuatl nesta cátedra, onde assistem, além dos alunos, intelectuais e pesquisadores, ajudou muito. $\mathrm{O}$ "dialeto" transfigurou-se em língua viva. A cultura Náhuatl é muito importante para a pesquisa dos estudos pré-hispânicos. Hoje temos muitas cátedras na universidade, mas esta foi a primeira, motivou e atribuiu importância a valorar mesmo as outras línguas e culturas pré-hispânicas.

\section{P: A cátedra tem tido alunos de todo o mundo, qual é a importância que motivou eles a assistirem essas aulas?}

R: Os temas pré-hispânicos têm sido como um ímã, muitos alunos estrangeiros do mundo inteiro vêm ao nosso encontro.

P: Na sua opinião, a criação de cátedras especificas sobre culturas e línguas indígenas nas universidades do Brasil poderia contribuir para o melhoramento das condições de vida desses povos nesse país?

R: Penso que sim. As cátedras são como um catalisador pois dinamizam energias criadoras. Por vezes as pessoas acham que uma língua falada só em pequenas regiões pelos indígenas que a herdaram dos antepassados, não possui utilidade, não tem sentido estudá-la. Porém, não devemos esquecer, que uma língua possui a cultura de toda dessa região, e precisamos resgatar a cultura que tem dentro.

A língua é a expressão de como eles experimentam uma sensação física no corpo ou na mente, o modo de ver e perceber as coisas. Felizmente, ter muitas línguas originarias é um tesouro que deve se aproveitar. Nesse sentido, as línguas ajudam imensamente à história de um povo e ao resgate de sua cultura ancestral. Tanto o México como o Brasil são fortunados de terem ainda sua diversidade cultural. 